determined by 99 technetium pertechnetate uptake69 was statistically significantly decreased at day 3 and 7 post-injection in animal treated with Ad-sIL1R2 Ig as compared to Ad-EGFP (10 animals per group, 2 experiments) but proteoglycan depletion of cartilage did not appear to be diminished.

Conclusion Our study demonstrated the value of a soluble IL1R2Ig chimeric protein has a IL1 inhibitor in vivo. It also demonstrated adenovirus-mediated gene expression allow for sufficient level of expression. But our preliminary data also raise new questions of the respective values and roles of IL1 or TNFa inhibition regarding acute inflammation and cartilage degradation.

\section{OP0034 INFLAMMATION-INDUCIBLE INTRA-ARTICULAR PRODUCTION OF HUMAN IL-1 RECEPTOR ANTAGONIST RESULTS IN MORE EFFICIENT INHIBITION OF COLLAGEN-INDUCED ARTHRITIS THAN DOES CONSTITUTIVE LOCAL EXPRESSION OF THE SAME TRANSGENE}

${ }^{1}$ FA Van de Loo, ${ }^{1} \mathrm{AC}$ Bakker, ${ }^{1}$ LA Joosten, ${ }^{1}$ OJ Arntz, ${ }^{2}$ AW Varley, ${ }^{2}$ RS Munford, ${ }^{1}$ WB Van den Berg. ${ }^{1}$ Rheumatology Research Laboratory; ${ }^{2}$ Molecular Host Defence Laboratory, UMC St-Radboud, Nijmegen, The Netherlands

\subsection{6/annrheumdis-2001.819}

Background Achieving biologically effective yet safe levels of recombinant anti-inflammatory proteins by gene therapy may require three regulatory features: 1) a basal level that is sufficiently low to avoid or minimise chronic immunosuppression 2) transcriptional regulation over a wide dynamic range, and 3) induced expression levels that are sufficiently high to achieve the desired biological effects. The C3-Tat/HIV promoter construct seems to have these properties. ${ }^{1}$ In this two-component expression system the complement factor 3 (C3) promoter regulates production of the HIV transactivator of transcription, and the Tat protein then stimulates expression of the desired transgene, which is regulated by the HIV-LTR promoter. Both C3 and HIV LTR promoters are inducible by proinflammatory cytokines.

Objectives To achieve disease-inducible expression of recombinant anti-inflammatory proteins in order to allow autoregulation of drug dose by natural homeostatic mechanisms.

Methods We compared a disease-inducible, two component expression system (C3-Tat/HIV) with the constitutive immediate early cytomegalovirus (ieCMV) promoter in the polyarticular Collagen-Induced Arthritis (CIA) model in mice. DBA/I mice were immunised with bovine type II collagen and boostered on day 22. On day 22, mice without any clinical signs of arthritis were selected and adenoviral vectors (Ad. CMV-Luc, Ad. CMVIL-1Ra, or Ad. C3-Tat/HIV-IL-1Ra) that contained luciferase or the human IL-1Ra gene under control of one of the two promoters were used to transfect the synovial lining of both knees. The injected knee joints and ipsilateral paws were then scored for signs of arthritis and at the end histology was taken.

Results Inducible promoter-driven IL-1Ra expression resulted in significantly improved inhibition of CIA than did CMV-driven IL-1Ra production. Moreover, overexpression of IL-1Ra in the knee joints also prevented CIA in the ipsilateral paws.

Conclusion Our data (1) demonstrate the feasibility of an inducible expression system for producing a recombinant transgene for treatment of arthritis and (2) show that this system is more effective than strong, constitutive transgene expression for preventing collagen-induced arthritis in mice.

\section{REFERENCE}

1 Varley AW, Geiszler SM, Gaynor RB, Munford RS. A two-component expression system that responds to inflammatory stimuli in vivoin vivo. Nat Biotechnol. 1997;15(10):1002-6

\section{OP0035 THE PRODUCTION OF CXCR3 AGONISTIC CHEMOKINES BY SYNOVIAL FIBROBLASTS FROM PATIENTS WITH RHEUMATOID ARTHRITIS}

${ }^{1} \mathrm{~A}$ Ueno, ${ }^{1} \mathrm{M}$ Yamamura, ${ }^{1} \mathrm{M}$ Iwahashi, ${ }^{1} \mathrm{~T}$ Aita, ${ }^{1} \mathrm{~A}$ Okamoto, ${ }^{2} \mathrm{~K}$ Nishida, ${ }^{2} \mathrm{H}$ Inoue, ${ }^{1} \mathrm{H}$ Makino. ${ }^{1}$ Department of Medicine III; ${ }^{2}$ Department of Orthopedic Surgery, Okayama University Medical School, Okayama, Japan

\subsection{6/annrheumdis-2001.820}

Background IFN-g-producing Th1 or Th0 cells predominate in the synovium of rheumatoid arthritis (RA). It is now known that the accumulation of Th1 cells is mediated by Th1 cell expression of the chemokine receptors CCR5 and CXCR3 and the local expression of their agonistic chemokines. Accordingly, $\mathrm{T}$ cell infiltrates in RA synoivum have been shown to mostly express CCR5 and CXCR3.

Objectives Since synovial fibroblasts are known as an active participant in joint destruction and chronic inflammation, we investigated the expression of CXCR3 agonists such as IP-10, Mig, and I-TAC in synovial fibroblasts, as well as synovial tissues from RA patients. In addition, the importance of these fibroblastderived chemokines in the chemotactic response of RA blood $\mathrm{CD}^{+}{ }^{+} \mathrm{T}$ cells was determined.

Methods Synovial fibroblast cell lines, prepared from RA synovial tissues, were incubated with or without IFN-g, IL-1, TNF-a, IL-17, or various combinations. Levels of protein and mRNA for IP-10, Mig, and I-TAC were measured by ELISA and RT-PCR, respectively. The distribution of chemokine-producing cells in RA synovial tissue was determined by immunohitochemistry. Fibroblasts were cultured overnight on chamber slides and their chemokine synthesis was detected by intracellular staining and a confocal laser scanning microscopy. The chemotactic response of RA blood $\mathrm{CD}^{+} \mathrm{T}$ cells to fibroblast culture supernatants with or without antibodies against IP-10, Mig, and I-TAC was determined by an in vitro chemotaxis microchamber technique.

Results Concentrations of CXCR3 agonistic chemokines in RA synovial fluid were much higher than those in RA peripheral blood or osteoarthritis (OA) synovial fluid. Immunohistochemical analysis of RA synovial tissue showed that these chemokines were expressed mostly on large cells and vascular endothelial cells in the sublining layer, as well as in the lining layer. The staining was prominent around the lymphocyte aggregate. Synovial tissues form RA more strongly expressed mRNA for all three CXCR3 agonists than OA tissues, and spontaneously released large amounts of their proteins. Synovial fibroblast cell lines isolated from RA, when stimulated with IFN-g, were able to produce these chemokines at the mRNA and protein levels, and this chemokine production was significantly augmented by IL-1, TNF-a, and IL-17. Culture supernatants of activated fibroblasts contained the chemotactic activity for blood CD4 ${ }^{+} \mathrm{T}$ cells from RA, and this activity was partially but significantly inhibited by antibodies against these CXCR3 agonists.

Conclusion These results indicate that synovial fibroblasts may contribute to the continued Th1 response in RA in part by secreting CXCR3 agonists. In addition, inflammatory cytokines derived from Th1 cells and macrophages, IFN-g, IL-17, IL-1, and TNF-a, are important inducers of these chemokines in the joint. 